\title{
Great challenges in structural geology and tectonics
}

\author{
Agust Gudmundsson* \\ Department of Earth Sciences, University of London Royal Holloway, Egham, UK \\ ${ }^{*}$ Correspondence: a.gudmundsson@es.rhul.ac.uk \\ Edited by: \\ Sonja L. Philipp, Georg-August-University of Göttingen, Germany \\ Reviewed by: \\ Valerio Acocella, Università Roma Tre, Italy
}

Keywords: plate tectonics, tectonic stresses, subduction zones, faults, earthquakes, dykes, volcanic eruptions, energy sources

Successful scientific theories provide theoretical understanding for reliable deterministic or probabilistic forecasting of events. In the past decades the volume of data obtained within the fields of structural geology and tectonics has increased enormously, but the theoretical understanding of the processes that generate these data has not advanced at the same rate. For example, after decades of research we still do not have successful theories explaining the size distribution of the Earth's tectonic plates or the processes that form, drive, and destroy them. Subduction zones certainly contribute to these processes; yet we do not know how these zones initiate. While the largest earthquakes occur in subduction zones, much of the fault slip is aseismic ("creep"). We do not know the conditions that determine whether slip on a fault will be seismic or aseismic, or small or large. Similarly, with dense geodetic and seismic networks on many active volcanoes, we should be able to make a reliable forecast of the propagation path of an injected dykebut normally we cannot. Dyke propagation and fault propagation depend on the energy available to drive these fractures. Our present knowledge of the energy budget of volcanic and seismic zones, however, is so limited that we cannot assess the maximum energies available for driving dyke-fed eruptions and earthquake faults. The topics listed here are among the great challenges in structural geology and tectonics. They all relate to the physics behind the observational data. Answering satisfactorily any of these challenges would constitute a major breakthrough in structural geology and tectonics.

\section{INTRODUCTION}

Structural geology and tectonics are closely related topics. Structural geology focuses primarily on the geometric description and the analysis of the spatial arrangement of structural features. It is also concerned with the forces or stresses or pressures that generate these structures-the result of brittle and/or ductile deformation-but to a lesser degree than tectonics. Tectonics focuses more on structures and processes on a larger scale, such as plate movements and mountain formation, as well as active processes and their physical causes. Its subfields include neotectonics, volcanotectonics, and seismotectonics.

There has been an enormous progress in obtaining high-quality tectonic/structural data in the past decade. This is largely due to greatly improved geodetic technique, in particular GPS and InSAR (Burgmann et al., 2000, 2006; Hooper et al., 2004; Wright et al., 2004; Fukushima et al., 2005; Sturkell et al., 2006; Delouis et al., 2010). The technique, described in detail by Dzurisin (2007) and Segall (2010), allows us to monitor active deformation within plate boundaries, including active fault zones and volcanoes worldwide.

Despite the new technique and wealth of data, we still cannot answer many of the basic questions related to tectonic processes, such as (Figure 1):

- What is the size distribution of Earth's tectonic plates, and how many are the plates?

- What are the main forces/processes that form, drive, and destroy the plates?

- How do subduction zones initiate?

- What physical conditions favor aseismic slip or creep ("slow earthquakes") on active faults?

- What conditions favor large seismic slips?
- Why is the fault-length/slip ratio so much larger than the faultlength/displacement ratio on the same faults?

- What is the likely path of an injected dyke during an unrest period in a volcano?

- Which energy sources are available to drive seismic and aseismic fault slip?

- Which energy sources are available to drive volcanic eruptions?

Other topics of great importance in structural geology and tectonics include (1) the conditions for the formation of transform faults vs. overlapping spreading centers; (2) how oblique-spreading ridge segments are initiated and maintained; (3) whether the mechanism of plate movements is primarily through fracturing or through flow; (4) the exact conditions for ductile vs. brittle deformation during crustal deformation; (5) general mountain-chain development; and (6) how fracture-related permeability in rocks is generated and maintained.

Here, however, the focus is on the bullet points listed above. These are all major challenges in structural geology and tectonics. Satisfactory answers to these challenges imply theories that are advanced enough to have testable implications and to make reliable forecasts as to likely scenarios for given boundary conditions and physical properties. The purpose of the paper is to outline and discuss these challenges.

\section{PLATES AND THEIR DRIVING FORCES}

The theory of plate tectonics was formulated in the 1960s, that is, close to half a century ago. It was formulated as a kinematic theory-focusing on plate movements without being too much concerned with the causes of the 


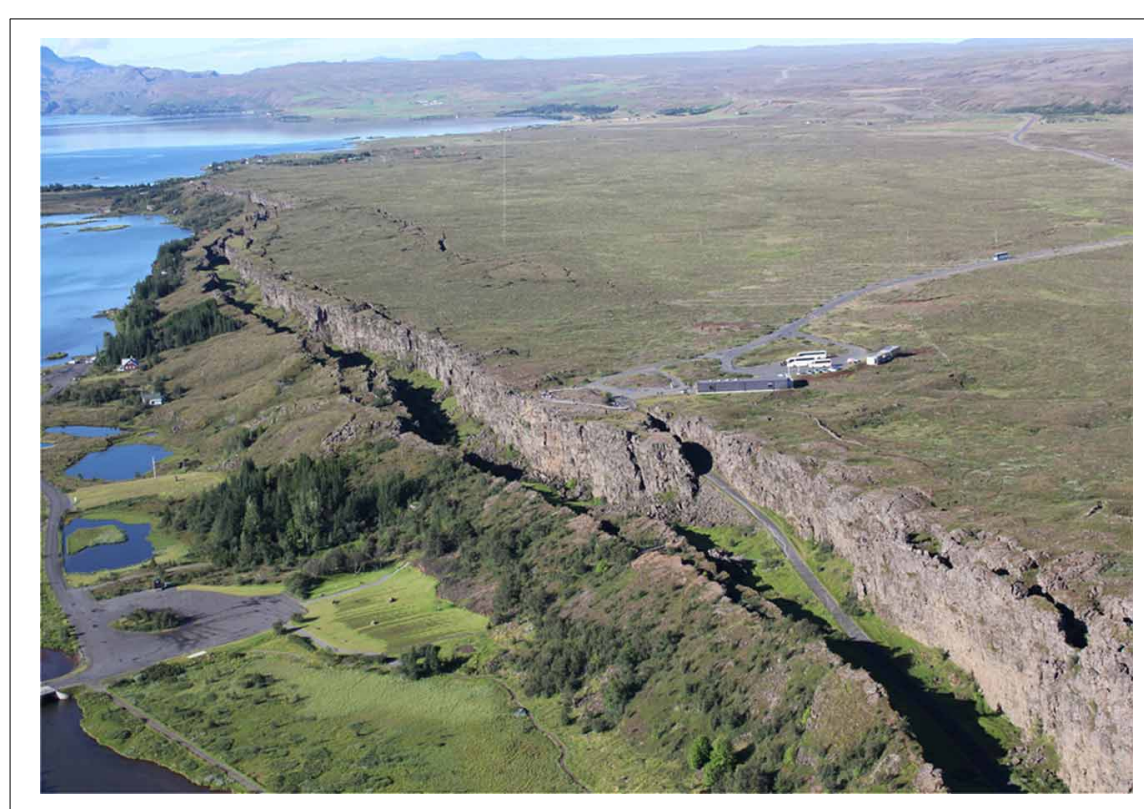

FIGURE 1 | Plate-tectonic driving forces. We can estimate the stresses needed to form a fault at a divergent plate boundary, such as here, but we do not know how the forces that cause those stresses and move the plates. Aerial view southwest, part of a large mixed-mode (opening and vertical displacement) normal fault in a Holocene pahoehoe lava flow of the rift zone in Southwest Iceland. The maximum opening of the fault is about $60 \mathrm{~m}$. Buses and houses provide a scale.

movements - and it still is. The kinematic details of the theory are now much better understood through the reconstruction of previous plate movements (e.g., Hall, 2002; Torsvik et al., 2008). Current plate motions are monitored by satellites and well established (DeMets et al., 1994, 2010). The forces or stresses that supposedly drive the plates, however, are still poorly understood, and so are the geometric characteristics of the plates themselves.

Consider first the plates. Originally, the plates were regarded as "rigid" parts of the Earth's lithosphere within which essentially no deformation took place; nearly all the deformation was supposed to take place at the plate boundaries. The boundaries were classified as divergent (primarily ocean ridges), convergent (primarily trenches and mountain chains), and transform (primarily transform faults-and their fracture-zone extensions). Initially, the main plates were defined as 7 , with about 12 additional smaller plates.

But solid fragments commonly follow power-law size distributions, and there is little reason why that sort of distribution should not hold for the fragmented lithosphere as well. In fact, recent studies show that the plates that have so far been identified follow roughly a power-law size (area) distribution. This was suggested by Bird (2003) and analyzed further by Sornette and Pisarenko (2003) and Morra et al. (2013), the latter showing that the abrupt change or "kink" in the scaling exponent on the log-log frequency-size plot of plates has been a permanent feature for the past $200 \mathrm{Ma}$. Similar changes in scaling exponents-resulting in different scaling regimes - are common; for example for the lengths and apertures of rock fractures (Gudmundsson and Mohajeri, 2013). The kinks relate to mechanical constraints and different fracture types. Short fractures (with small apertures) are mostly tension fractures and confined to single mechanical layers, whereas longer fractures are mostly normal faults and penetrate many mechanical layers. Similar constraints may occur as regards the platesthe small ones being more constrained laterally (Bird, 2003; Morra et al., 2013) and/or vertically. But this needs to be explored.

How many are the plates? In the original plate-tectonic theory there were, as said, 7 main plates and about 12 smaller plates. In the analysis of Sornette and Pisarenko (2003) there are 42 plates, but the revised number used by Bird (2003) is 52 plates. In what is presumably the most up-to-date counting (List of tectonic plates, Wikipedia, 2013) there are 7 primary plates, 8 secondary plates, and $57-58$ tertiary plates, bringing the total to about 73 plates. If plate-size distribution indeed follows a power law, there is no particular reason why the minimum plate size should be limited to tertiary plates. The exact number would depend on the definition of a tectonic plate which, in turn, depends on our theoretical understanding of the formation, destruction, and driving forces of plates.

While the power-law distribution of plate sizes is not surprising, its demonstration by actual data is a step forward in understanding the mechanism of plate formation and evolution. Power laws are very common in natural and social sciences and constitute a class of heavy-tailed distributions (Turcotte, 1997; Barabasi and Albert, 1999; Sornette, 2006; Clauset et al., 2009; Pisarenko and Rodkin, 2010). Generally, it is agreed that power-law size distributions occur when the sizes of events/objects are dependent whereas, by contrast, normal distributions occur when the sizes of events/object sizes are independent. Several mechanisms have been proposed for power laws, including entropy maximizing, self-organized criticality, and preferential attachment. However, none of these mechanisms really explains why certain processes and objects and events follow powerlaw size distributions, whereas others do not.

While the plate areas thus seem belong to the class of objects whose size-distributions follow power laws, the forces/stresses moving the plates are still largely unknown (Figure 1). Many possible forces have been suggested, including those related to mantle convection and the Earth's rotation, but the main forces are still considered to be "ridge push" and "slab pull." Ridge push has normally been primarily attributed to elevation difference between ocean ridges and the surrounding ocean floor. Gravity sliding of a plate away from an elevated ridge generates a push, a horizontal compressive force or stress, in the surrounding part of the lithosphere (Frisch et al., 2011). However, an additional stress, usually ignored in calculations of ridge push, is 
generated by the magmatic overpressure of the dykes injected within the active zone of rifting at mid-ocean ridges (the neovolcanic zone). The overpressure can reach as much as tens of mega-pascals (e.g., Becerril et al., 2013). The contribution of overpressure associated with dyke injection to ridge push is well established through horizontal compressive stresses (generated by the overpressured dykes) and associated excess spreading rates in recent rifting episodes in Iceland and the East African Rift (Wright et al., 2012). Slab pull, however, is commonly regarded as the main mechanism for driving the plates. The pull is supposed to be generated by the down-going (sinking) slabs in the subduction zones. A slab sinks because of its comparatively high density and it is thought to drag the associated plate with it, that is, to generate a tensile force or stress, hence the name plate pull. But so long as we do not know how subduction zones initiate, it is difficult to assess this force and its likely changes in the near future.

\section{SUBDUCTION-ZONE INITIATION}

Subduction zones are a key element in the theory of plate tectonics (Figure 2). It has been known for a long time that the plates velocities tend to be much higher for plate whose margins are partly subduction zones (Forsyth and Uyeda, 1975; Schellart et al., 2007). Consequently, it is thought that subduction zones contribute to the plate motion through the drag or pull effect of the sinking slab. Individual subduction zones range in length or strike dimension from 250 to $7400 \mathrm{~km}$ (Schellart et al., 2007). By implication, the associated thrust faults have similar strike dimensions and reach dip dimensions (widths in seismology) of at least hundreds of kilometres. The cumulative length of the subduction zones is about $55,000 \mathrm{~km}$ (Stern, 2002; Frisch et al., 2011), whereas that of the mid-ocean ridges is variously estimated at $60-80,000 \mathrm{~km}$ (e.g., Macdonald, 1982; Stern, 2002; Mid-ocean ridge, Wikipedia, 2013). The active spreading portion of the mid-ocean ridge system is regarded as somewhat shorter-perhaps $55-60,000 \mathrm{~km}$. The cumulative length of a fracture system, however, depends on its irregularity and the scale and method used for the length measurement; the "exact"

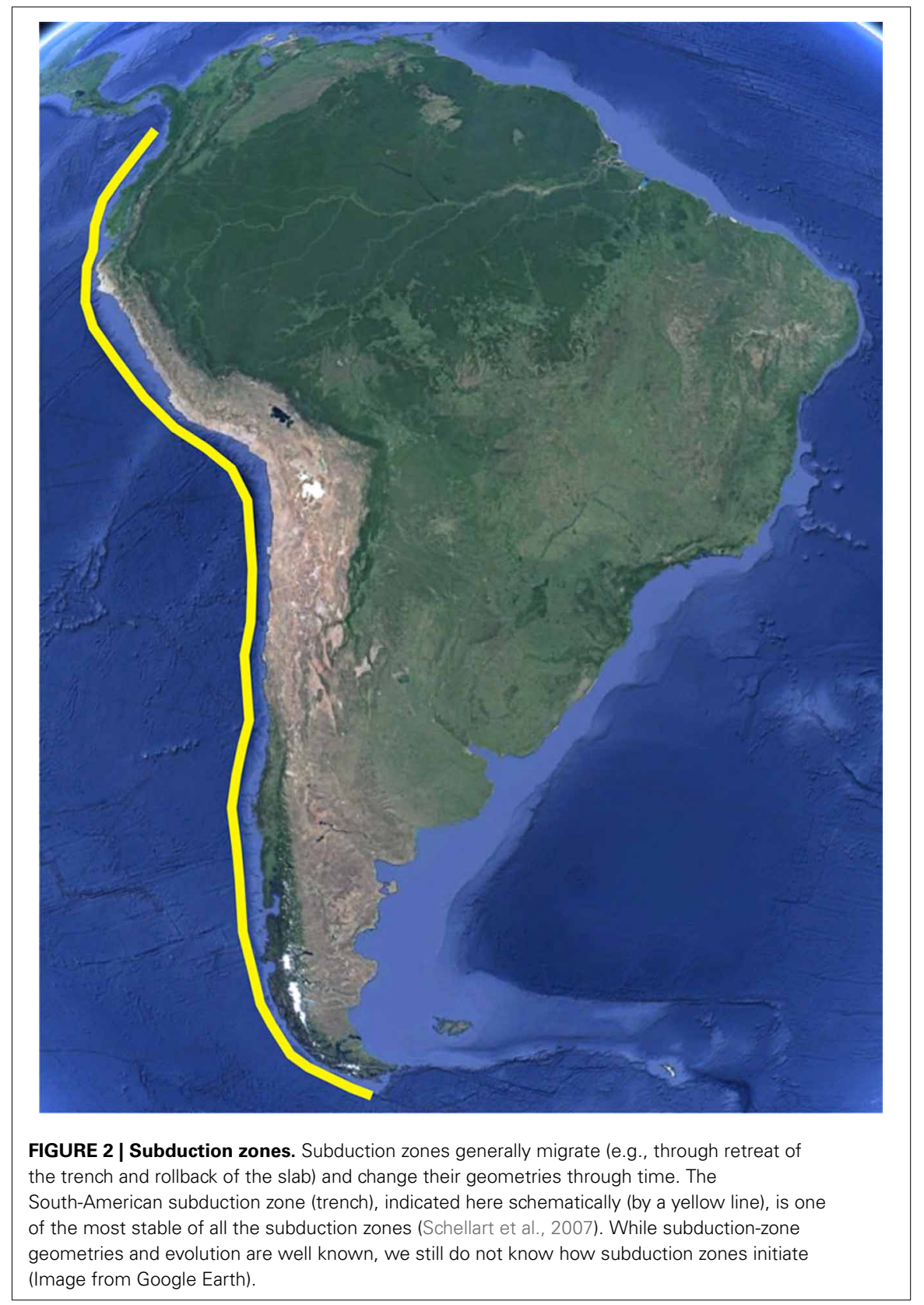

cumulative lengths of these structures thus cannot be determined.

Given that plate pull is regarded as the main driving force of plate movements, understanding the initiation and evolution of subduction zones is of great importance. A new subduction zone normally changes the plate configuration, the plate movements, and the associated forces. Thus, we can understand the long-term future plate movements, as well as past movements, only if we have a theoretical framework that makes it possible to understand and forecast subduction zone initiation.

There has been considerable work on subduction-zone initiation in the past decade (e.g., Stern, 2002, 2004; Hall et al., 2003; Niu et al., 2003; Gurnis et al., 2004; Gerya et al., 2008; Duarte et al., 2013). The initial idea (when plate-tectonics was established) was as follows: As the oceanic lithosphere moves from the ocean ridges and becomes older, its thickness (partly through cooling of the upper asthenosphere) and density increase until its 
density exceeds that of the asthenosphere and the plate starts to sink. The sinking was supposed to generate the subduction zone. Mere aging of the lithosphere, however, does not seem to be a plausible explanation for subduction-zone initiation; other factors are needed (Cloetingh et al., 1989). Adding sediment load and water-weakening of the lithosphere may possibly help to initiate subduction at passive margins (Regenauer-Lieb et al., 2001), but this idea has still not been formulated as a compelling theory.

Another widely discussed idea is that subduction zones initiate on existing weaknesses, discontinuities of some sort, in the lithosphere. Discontinuities identified as potential or actual sites for subduction-zone initiation include fracture zones, back arcs, spreading centers, and former (extinct) subduction zones (Gurnis et al., 2004; Duarte et al., 2013). The most widely considered discontinuities for subduction-zone initiation are transform faults/fracture zones. The mechanism of changing a fracture into a subduction zone has been analyzed numerically (Hall et al., 2003; Gurnis et al., 2004). The results indicate that:

1. At least $100 \mathrm{~km}$ of forced convergence is needed before the stage of selfsustaining subduction is reached.

2. The fracture zone must be subject to considerable horizontal compressive force or stress in order to initiate subduction. This stress was initially estimated at $80 \mathrm{MPa}$ by McKenzie (1977), but may be somewhat lower depending on the boundary conditions.

The two main models of subduction initiation, namely (a) increase in lithosphere density and sedimentary load with age, resulting in instability and subsidence, and (b) forced convergence, particularly at fracture zones, are both possible and not necessarily exclusive. Both models, however, face certain theoretical and observational difficulties that need to be overcome before reliable forecasts based on these models could be made.

For model a, the subduction zones could be expected to be at a certain, roughly constant, distance from the nearby ocean ridges, but these distances vary widely. One explanation for the variation in distance is that both ridges (Gudmundsson, 1995) and subduction zones (Schellart et al., 2007, 2011) migrate with time. But migration of ridges and subduction zones does not explain the great variation in distances between these two. If the sedimentary load is added, then a certain critical load, for a given lithosphere strength, might be expected to initiate subduction, but there is little evidence for this actually happening-witness, for example, the lack of subduction zones at the continental margins of the Atlantic Ocean.

As for model b, one difficulty is lack of specification: which of the many discontinuities with a potential of changing into subduction zones actually do so and why? There are many fracture zones that could potentially change into subduction zones once a new ridge segment forms that is parallel with the fracture zones in a given area. Also, there are numerous ridge-parallel discontinuities in any tectonic plate that are subject to ridge push and yet do not, as a rule, change into subduction zones. Ridge-parallel discontinuities include large normal faults, some with displacements of hundreds of meters or several kilometers and cutting through the entire lithosphere. With dips of $50-70^{\circ}$, it should be easier to transform them into subduction zones than vertical strike slip faults in fracture zones (fracture zones also contain many normal faults, however). But there is no clear evidence that any of the large normal faults in the ocean floor or on the continental shelf have changed into subduction zones. Similarly, the contacts between continental crust and the oceanic crust are discontinuities that are subject to horizontal ridge-push stresses; yet few develop into subduction zones. Thus, while these and related models certainly indicate several possibilities as to subduction imitation, it is fair to conclude that we do not yet have a general quantitative theory-one with a clear explanatory power-as to subduction-zone initiation.

\section{SEISMIC AND ASEISMIC SLIP}

In the past few decades, the importance of aseismic slip has become recognized as fundamental in active fault zones (Figure 3). In fact, aseismic slip is so common that it is estimated that in subduction zones and transform faults, for example, some $50 \%$ of the slip may be aseismic (Stein and Wysession, 2003; Peng and Gomberg, 2010). Slip is referred to as aseismic when it is

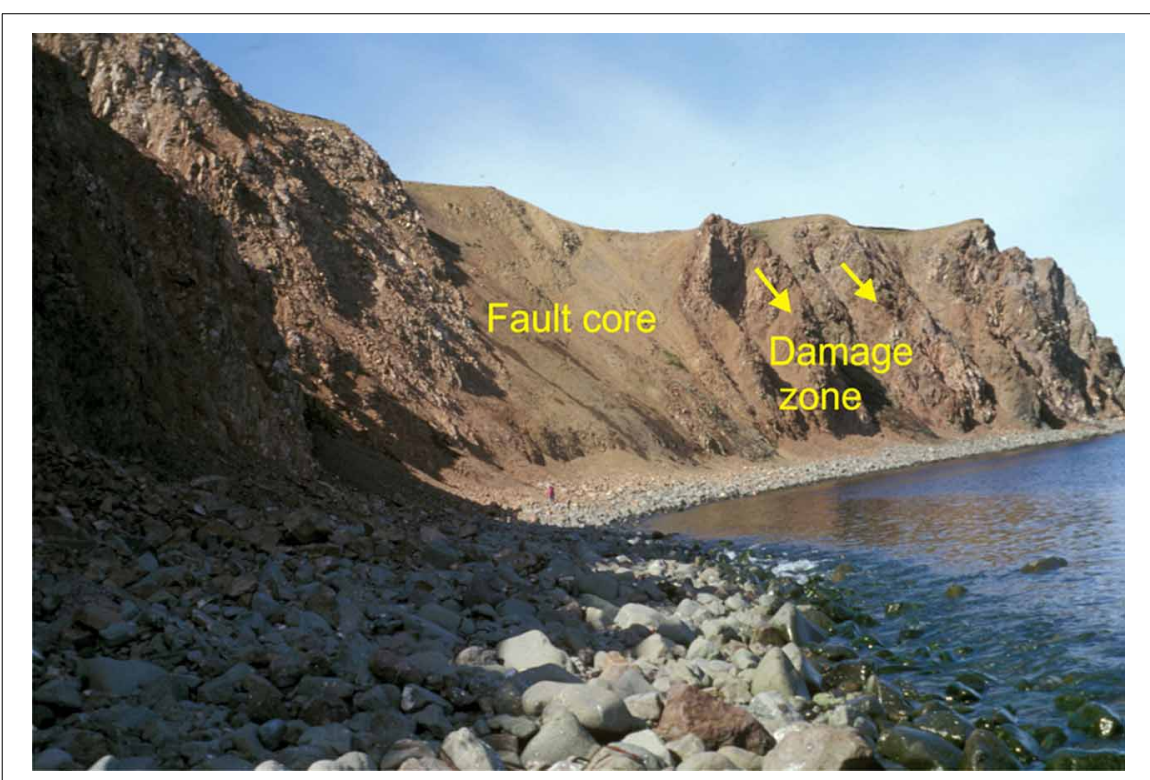

FIGURE 3 | Seismic and aseismic slip. Fault zones are composed of a core and a damage zone. View west, the core and the damage zone of a part of the Husavik-Flatey transform fault, which is partly exposed on land in North Iceland (Gudmundsson, 1995, 2000). The core is $10 \mathrm{~m}$ thick and the lava flows in the damage zone, originally sub-horizontal, now dip $40^{\circ} \mathrm{NW}$. The core is composed of soft breccia and presumably subject to much aseismic slip, whereas the fault as a whole is seismically highly active. 
comparatively slow and not accompanied by an ordinary earthquake. There are many other terms used in seismotectonics for aseismic slip such as "slow earthquake," "creep" in the uppermost part of fault zones, and "slow-slip phenomena” (Sleep and Blanpied, 1992; Galehouse and Lienkaemper, 2003; Jordan, 2003; Rolandone et al., 2008; McFarland et al., 2009; Peng and Gomberg, 2010). Aseimic slip occurs partly through "afterslip" and partly through creep, but in this overview the term used for all these processes is aseismic slip.

Why is part of the displacement on an active fault generated through aseismic slip and part through seismic slip? More generally: Why do surface (and subsurface) rocks sometimes respond to generally similar boundary conditions through flow and sometimes through fracture? At present, we do not know the detailed answers to these questions. We know that strain rate, mechanical properties (and asperities), and temperature affect the response of rocks to loading. However, even when all the conditions are generally similar, the rock response may sometimes vary from ductile to brittle; for example, in many mountain chains and in individual fault zones (Figure 3).

One possible explanation for the common aseismic slip is that it is a partly the result of a "correction" or adjustment of the slip to that which would have occurred if the dynamic Young's modulus were equal to the static Young's modulus (Gudmundsson et al., 2013). These moduli are very different; the dynamic modulus, which controls co-seismic slip, is commonly 10-times and may be 100-times larger than the static modulus of the core and the innermost part of the damage zone of a fault zone (Figure 3). The static modulus of the core and innermost part of the damage zone then controls the aseismic slip. The rock behavior may be regarded as analogous to an elastic-plastic model in continuum mechanics where to an initial elastic strain or displacement (the seismic slip) a ductile strain (the aseismic slip) is gradually added. This model may also account for the 1-2 order of magnitude difference between the length-slip ratios in individual earthquakes and the lengthcumulative displacement in the same fault zones.
Whether or not this model is along fruitful lines, understanding the conditions for seismic and aseismic slip is of fundamental importance in tectonics and structural geology in general and in earthquake mechanics in particular. The magnitude of aseismic slip has come as a surprise to many, and the topic relates to the question of conditions that favor ductile over brittle deformation. Furthermore, this topic relates directly to the conditions for the initiation of fault slip, aseismic and seismic, and therefore to earthquake mechanics.

\section{LARGE FAULT SLIPS AND EARTHOUAKES}

Fault zones are three-dimensional structures composed of fault cores and damage zones (Figure 3; Bruhn et al., 1994; Caine et al., 1996; Shipton and Cowie, 2003; Kim et al., 2004; Faulkner et al., 2006). Because the mechanical properties of the damage zone and, in particular, the core, are normally widely different from those of the host rock, the fault zone develops a local stress field that may be very different from the surrounding regional stress field (Gudmundsson et al., 2010). The local stress in a fault zone determines if and when slip occurs and, presumably, whether the slip will be seismic or aseismic. Simple elastic dislocation models miss entirely the internal structures and properties of fault zones, namely the factors that, to large degree, control earthquakes and aseismic slip (and faultzone permeability). Such models, however, may be useful for matching the general co-seismic surface deformation (Segall, 2010).

Earthquake fractures are dynamic cracks, for which considerable body of knowledge exists (Freund, 1998; RaviChandar, 2004; Shulka, 2006). Much of this literature, however, focuses on the propagation of mode I cracks (extension fractures such as tension fractures and dykes in rift zones) rather than shear fractures (mode II, mode III, or mixedmode cracks), as earthquake faults are. There are also specific monographs on earthquake source mechanics (Kostrov and Das, 2005).

We know that earthquakes occur on faults, and that the faults develop from existing weaknesses such as joints-which are commonly generated when the rock forms (Figure 4). In the simplest terms, earthquake initiation can be understood through considerations of stresses and material properties. For example, we know that increasing the pore-fluid pressure in the crust, such as during injection of water into reservoirs or the building of dams, triggers earthquakes. These triggering effects are reasonably well understood through elementary stress analysis and presentable by Mohr circles, as is routinely done in textbooks on structural geology and tectonics. The main unsolved problem, however, is to explain why some earthquake slips become large, generating large earthquakes, whereas most remain small (e.g., Main and Naylor, 2012). This brings us again to the power-law size distribution that we discussed in connection with tectonic plate-size distributions.

The Gutenberg-Richter frequencymagnitude relation for earthquakes is among the best known of all the power laws in physical science. The Omori relation for the rate of aftershock production with time since the main shock, and the Bath's relation, indicating that the difference in magnitude between the main shock and the largest aftershock is nearly a constant, are also well known earthquake relations (Turcotte et al., 2007). Other scaling laws refer to the geometric aspects of the seismogenic faults, perhaps the most remarkable being the great difference between the rupture length-slip ratios and the fault length-displacement ratios. Commonly, the rupture length-slip ratios are of the order of $10^{3-4}$ (Wells and Coppersmith, 1994; Leonard, 2010) whereas the fault length-displacement ratios are of the order of $10^{1-2}$ (e.g., Clark and Cox, 1996; Schlische et al., 1996). These ratios thus differ by factors of the order of $10^{1-2}$.

None of the relations discussed above explains why earthquake magnitudes follow power law size distributions-why some earthquakes are very large while most are small. It is known from studies of fault zones and fissure swarms, however, that fault-size distributions also follow power laws (e.g., Gudmundsson and Mohajeri, 2013). Since fault slip is a function of fault size (the controlling dimension, which is either the strike dimension or the dip dimension), and 


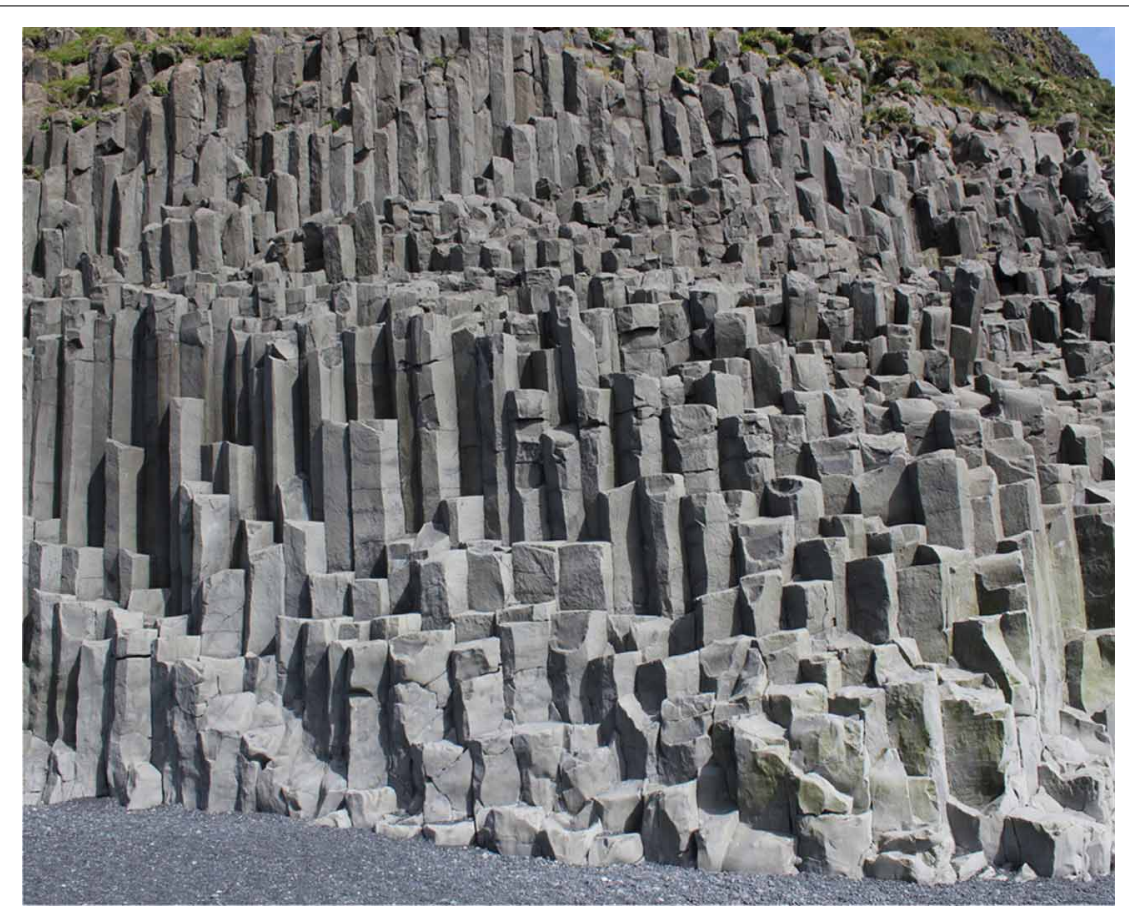

FIGURE 4 | Fault initiation and earthquakes. Most faults originate from existing weaknesses that, on an outcrop-scale, are commonly joints generated during the formation of the rock. View east, columnar (cooling) joints in a basaltic intrusion in South Iceland, with a common column diameter (width) of $20-40 \mathrm{~cm}$.

since earthquake moments (energies) and related magnitudes depend on slip and rupture area, it could be argued that when the fault sizes follow power laws, so must the magnitudes. More specifically, if we could explain the power-law size distribution of fault dimensions, the power laws in earthquake energy releases and magnitudes might follow. At the moment, however, no power laws have been satisfactory explained in terms of well-developed physical theory (Turcotte, 1997; Barabasi and Albert, 1999; Sornette, 2006; Clauset et al., 2009; Pisarenko and Rodkin, 2010). The development of such a theory is one of the most important tasks in science in general, and in tectonics and earthquake mechanics in particular.

\section{FEEDER-DYKE PROPAGATION}

Volcanic activity is often marginalized, or excluded altogether, in mainstream research in structural geology and tectonics. For example, many textbooks on structural geology hardly mention dykes, sills, and inclined sheets at all. Yet, all these are rock fractures; more specifically, fluid or magma-driven fractures (Figure 5) and thus part of general brittle deformation.
Most importantly, hardly any eruptions occur unless a magma-driven fracture is able to form and propagate to the Earth's surface. Dyke propagation is essentially that of a mode I crack, that is, an extension fracture; the same crack model is also used for all tension fractures in rift zones and at divergent plate boundaries as well as for most joints (Gudmundsson, 2011). Dyke (and sheet) propagation is and should be regarded as an important part of structural geology and tectonics-in fact, a major part of the fields of neotectonics and volcanotectonics.

Dyke propagation is generally simpler than seismogenic fault propagation. This follows partly because dyke propagation is essentially quasi-static mode I crack propagation. By contrast, earthquake fracture is a dynamic mode II or mode III, and commonly mixed mode, shear-fracture propagation. Also, many dyke fractures are geometrically simple (Figure 5). Each dyke segment is normally composed of essentially one fracture, and its geometry can be analyzed in detail because it is filled with solidified magma. Dyke propagation does normally not generate much of a damage zone or core, partly because most dykes are not subject to reactivation (they are single injections, Figure 5). By contrast, an earthquake fault is commonly reactivated many times and generates a fault core and damage zone (Figure 3). Some damage zones are composed of many layers or subzones (Gudmundsson et al., 2010) and contain a very large number of extension fractures and small faults in addition to the main-fault segments.

Despite dyke-fractures being comparatively simple, their propagation paths are commonly anything but. This is demonstrated by direct field observations (Geshi et al., 2010; Gudmundsson, 2011, 2012) which show many dykes being deflected into sills or inclined sheets along parts of their paths. In addition, in any particular dyke area, most of the dykes become arrested and thus never reach the surface to supply magma to eruptions (Figure 5). The complex paths of magma-driven fractures are also indicated by detailed geodetic and seismic studies of volcano unrest periods. In many very well-monitored recent volcano unrest periods, with wealth of seismic and geodetic data, it has proven impossible to provide reliable forecasts as to either the path of the dyke or the likelihood of its erupting at the surface. Monitoring indicates that many dykes become arrested, others change into sills, and then back to dykes, in agreement with field observations. The likelihood as to the dyke making it to the surface is generally difficult to assess. When a dyke eventually reaches the surface, there are still no reliable methods for forecasting the likely duration and size of the resulting eruption (Gudmundsson, 2012), both of which depend on the energy available to drive the eruption.

\section{ENERGY SOURCES DRIVING EARTHQUAKES AND ERUPTIONS}

The formation and propagation of every rock fracture, including dykes (Figure 5) and slipping faults (Figures 1, 3, 6), requires energy. More specifically, the propagation of a fracture requires surface energy, that is, energy to rupture the rock and form the two fracture surfaces (Anderson, 2005; Gudmundsson, 2011). Thus, for a magma-driven fracture and an earthquake fracture to propagate, energy inputs into the volcano and fault zone are needed. 


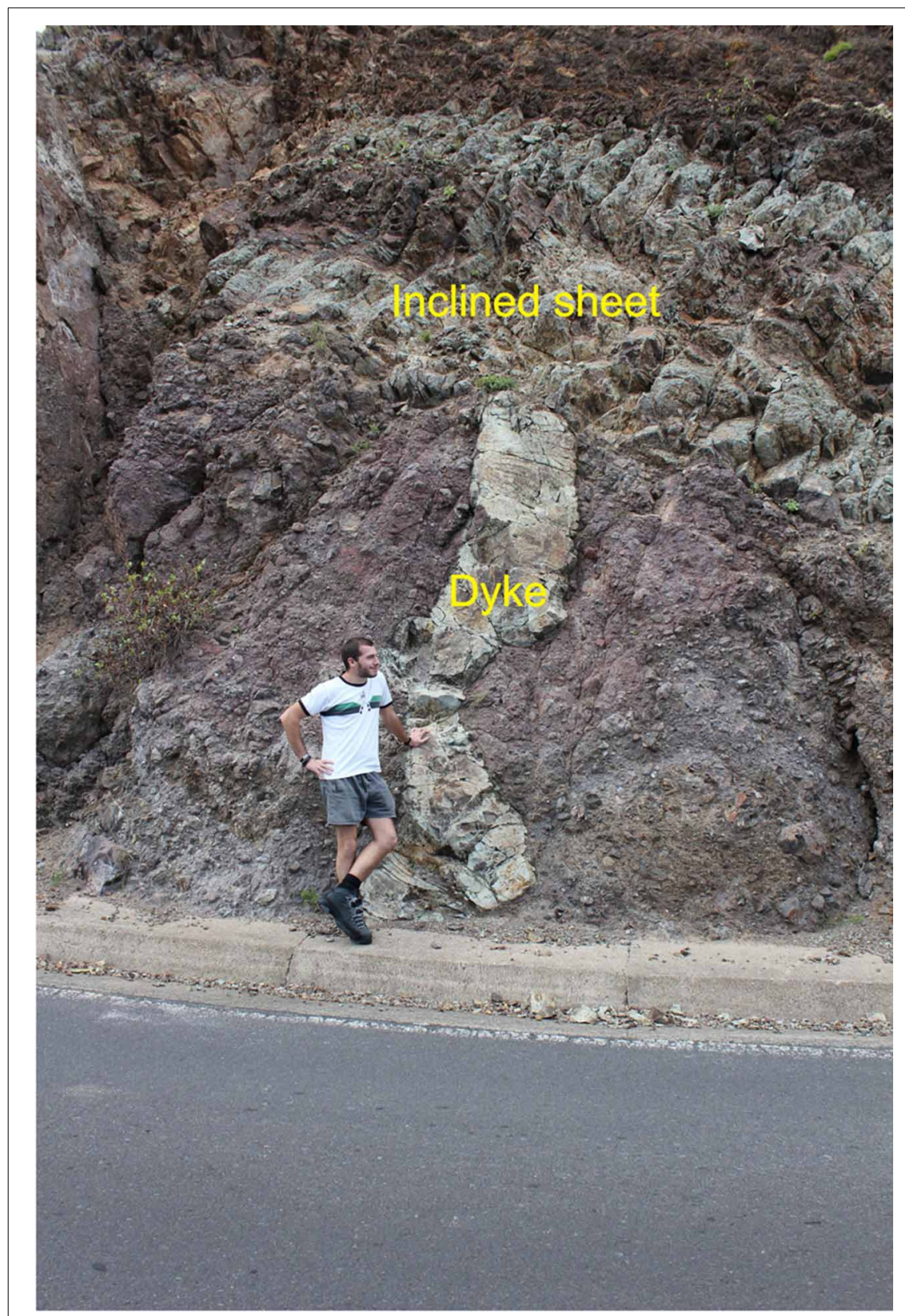

FIGURE 5 | Dyke propagation. Dyke paths are complex and cannot, at this stage of theoretical understanding, be reliably forecasted during unrest periods in volcanoes. Many dykes become arrested, particularly at contacts between mechanically dissimilar rocks, like this basaltic dyke in Tenerife (Canary Islands). The soft rock hosting the dyke is altered breccia, whereas the stiff rock arresting the dyke is an older, inclined sheet.

There is work done on, and therefore increase in internal energy of, fault zones and volcanic zones by plate-tectonic forces (Figures 1, 6); in addition, there is heat input through the general heat flow as well as magma intrusion. The heat received by volcanic zones is primarily from magma chambers and reservoirs, as well as from dyke and sill and sheet injections. Some from the seismic moment (Aki, 1966; Aki and Richards, 2009) and the related moment-magnitude scale (Hanks and Kanamori, 1979). A small fraction of the released energy is radiated as seismic waves, but the greatest part is transformed into heat (partly because of friction) and surface energy needed for the seismic rupture (the earthquake fault) to propagate. The exact proportion of the energy released into seismic waves is not really known (e.g., Stacey and Davis, 2008), but is thought to be somewhere around $10 \%$ of the total. Similarly, the surface energy needed to propagate a dyke to the surface and supply magma to an eruption can be estimated (Gudmundsson, 2012). Because of the logarithmic scales of the earthquake magnitudes, as well as of the explosive index for volcanic eruptions, the largest earthquakes/eruptions entirely dominate the energy release or transformation in a given zone.

How much of the energy received by fault zones is available to drive seismogenic faulting is not well known (Figure 6). For example, we do not know how much of the energy received by a major fault zone is transformed into aseismic slip and general ductile deformation, small earthquakes, extension fracturing (hydrofracture or mineral-vein formation), and dissipated as heat. Nor do we know how much of the energy-primarily elastic energyin the fault zone just before a potential major earthquake is actually available to drive the fault propagation. These energy considerations, which must be formulated in terms of thermodynamic principles, have not received the attention they deserve. At present, these energy proportions are poorly constrained but need to be well constrained in order to understand the potential of an active fault zone for generating large to great earthquakes.

Stress drops, the driving shear stresses for seismogenic faulting, are mostly small, commonly 1-10 MPa (Aki and Richards, 2009), and constitute only a fraction of the total stress in the fault zone. Since slip on a fault relates to the driving stress and partly determines the energy (moment) of the earthquake, the driving stress is not an indication of the total stress or the total energy in a fault zone. Also, the boundary conditions 


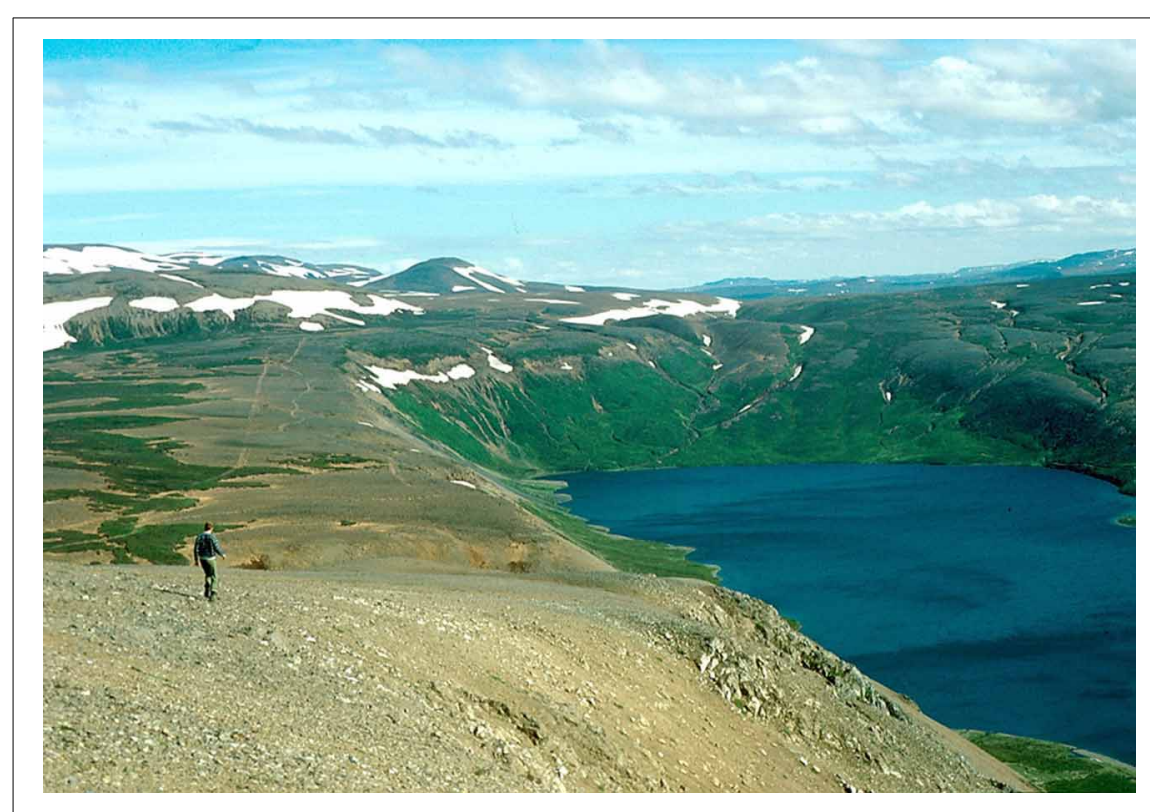

FIGURE 6 | Energy sources driving earthquakes. Major fault zones receive much energy (primarily elastic energy) through plate movements. View east, part of the Husavik-Flatey transform fault in North Iceland (Figure 3, Gudmundsson, 1995, 2000) showing a sag pond (Lake Botnsvatn) formed along normal faults. We still do not know of much of the energy stored in fault zones is available to drive large-scale seismogenic faulting.

of the fault zone partly determine the energy available during the earthquakefault propagation. If the boundaries are rigid (so-called fixed grip) then they do not contribute to the available energy. By contrast, if the boundaries are flexible, then their movement (that is, work) during the fault propagation may provide significant energy input and increase the chances of the generation of large to great earthquakes (Gudmundsson, 2012). In general, the energy budget and available energy in seismogenic zones remain poorly known.

Similarly, for volcanic zones and individual volcanoes, the energy available to propagate a feeder dyke to the surface and then squeeze out magma from the chamber remains poorly constrained (Gudmundsson, 2012). Heat is continuously transported into volcanoes, particularly through their magma chambers, but its transformation into mechanical energy and work is inefficient and difficult to estimate. Elastic energy is stored in the volcano during magma-chamber inflation. In addition, the flanks of the volcano, or the boundaries of the associated volcanic zone, may be flexible, in which case energy can be brought into the system (through work) during feeder-dyke propagation. In order to assess volcanic risks when a volcano is subject to unrest and inflation, particularly as regards the likely size and duration of the eventual eruption, we must know the energy available to propagate the feeder dyke and sustain the eruption. At the moment, we have no detailed theoretical framework to make accurate estimates of this energy. The development of such a framework as well as a framework for estimating the available energy in seismogenic zones are among the main challenges in structural geology and tectonics.

\section{ACKNOWLEDGMENTS}

I thank the Frontiers reviewer and the associate editor for helpful comments.

\section{REFERENCES}

Aki, K. (1966). Generation and propagation of G waves from the Niigata Earthquake of June 16, 1964. Part 2. Estimation of earthquake moment, released energy, and stress-strain drop from the $\mathrm{G}$ wave spectrum. Bull. Earthq. Res. Inst. 44, 73-88.

Aki, K., and Richards, P. G. (2009). Quantitative Seismology. 2nd Edn. Herndon, VA: University Science Books.

Anderson, T. L. (2005). Fracture Mechanics. 3rd Edn. New York, NY: CRC Press.
Barabasi, A. L., and Albert, R. (1999). Emergence of scaling in random networks. Science 286, 509-512. doi: 10.1126/science.286.5439.509

Becerril, L., Galindo, I., and Gudmundsson, A. (2013). Depth of origin of magma in eruptions. Sci. Rep. 3, 2762. doi: 10.1038/srep02762

Bird, P. (2003). An updated digital model of plate tectonics. Geochem. Geophys. Geosyst. 4. doi: 10.1029/2001GC000252

Bruhn, R. L., Parry, W. T., Yonkee, W. A., and Thompson, T. (1994). Fracturing and hydrothermal alteration in normal fault zones. Pure Appl. Geophys. 142, 609-644. doi: 10.1007/BF00 876057

Burgmann, R., Hilley, G., Ferretti, A., and Novali, F. (2006). Resolving vertical tectonics in the San Francisco Bay area from permanent scatterer InSAR and GPS analysis. Geology 34, 221-224. doi: 10.1130/G22064.1

Burgmann, R., Rosen, P. A., and Fielding, E. J. (2000). Synthetic aperture radar interferometry to measure Earth's surface topography and its deformation. Annu. Rev. Earth Planet Sci. 28, 169-209. doi: 10.1146/annurev.earth.28.1.169

Caine, J., Evans, J. P., and Forster, C. B. (1996). Fault zone architecture and permeability structure. Geology 24, 1025-1028. doi: $\quad 10.1130 / 0091-7613(1996) 024<1025$ : FZAAPS $>2.3 . \mathrm{CO} ; 2$

Clark, R. M., and Cox, S. J. D. (1996). A modern regression approach to determining fault displacement-scaling relationships. J. Struct. Geol. 18, 147-152, 1996. doi: 10.1016/S0191-8141(96)80040-X

Clauset, A., Chalizi, R. C., and Newman, M. E. J. (2009). Power-law distributions in empirical data. Soc. Ind. Appl. Math. 51, 661-703. doi: 10.1137/070710111

Cloetingh, S., Wortel, R., and Vlaar, N. J. (1989). On the initiation of subduction zones. Pure Appl. Geophys. 129, 7-25. doi: 10.1007/BF00874622

Delouis, B., Nocquet, J. M., and Vallee, M. (2010). Slip distribution of the February 27, 2010 Mw $=8.8$ Maule Earthquake, central Chile, from static and high-rate GPS, InSAR, and broadband teleseismic data. Geophys. Res. Lett. 37. doi: 10.1029/2010GL043899

DeMets, C., Gordon, R. G., and Argus, D. F. (2010). Geologically current plate motions. Geophys. J. Int. 181, 1-80. doi: 10.1111/j.1365-246X.2009.04491.x

DeMets, C., Gordon, R. R., Argus, D. F., and Stein, S. (1994). Effects of recent revisions to the geomagnetic reversal time scale on estimates of current plate motions. Geophys. Res. Lett. 21, 2191-2194. doi: 10.1029/94GL02118

Duarte, J. C., Rosas, F. M., Terrinha, P., Schellart, W. P., Boutelier, D., Gutscher, M. A., et al. (2013). Are subduction zones invading the Atlantic. Evidence form the southwest Iberia margin. Geology 41, 839-842. doi: 10.1130/G34100.1

Dzurisin, D. (2007). Volcano Deformation: New Geodetic Monitoring Technique. Berlin: Springer Verlag.

Faulkner, D. R., Mitchell, T. M., Healy, D., and Heap, M. J. (2006). Slip on weak fault by the rotation of regional stress in the fracture damage zone. Nature 444, 922-925. doi: 10.1038/nature05353

Forsyth, D., and Uyeda, S. (1975). On the relative importance of the driving forces of plate 
motion. Geophys. J. R. Astr. Soc. 43, 163-200. doi: 10.1111/j.1365-246X.1975.tb00631.x

Freund, L. B. (1998). Dynamic Fracture. Cambridge: Cambridge University Press.

Frisch, W., Meschede, M., and Blakey, R. (2011). Plate Tectonics: Continental Drift and Mountain Building. Berlin: Springer Verlag.

Fukushima, Y., Cayol, V., and Durand, P. (2005). Finding realistic dike models from interferometric synthetic aperture radar data: the February 2000 eruption at Piton de la Fournaise. J. Geophys. Res. 110. doi: 10.1029/2004JB003268

Galehouse, J. S., and Lienkaemper, J. J. (2003). Inferences drawn from two decades of alinement array measurements of creep on faults in the San Francisco Bay region. Bull. Seismol. Soc. Am. 93, 2415-2433. doi: 10.1785/0120020226

Gerya, T. V., Connolly, J. A. D., and Yuen, D. A. (2008). Why is terrestrial subduction one-sided. Geology 36, 43-46. doi: 10.1130/G24060A.1

Geshi, N., Kusomoto, S., and Gudmundsson, A. (2010). Geometric difference between non-feeder and feeder dikes. Geology 38, 195-198. doi: 10.1130/G30350.1

Gudmundsson, A. (1995). Stress fields associated with oceanic transform faults. Earth Planet. Sci. Lett. 136, 603-614. doi: 10.1016/0012-821X(95)00164-8

Gudmundsson, A. (2000). Dynamics of volcanic systems in Iceland: example of tectonism and volcanism at juxtaposed hot spot and mid-ocean ridge systems. Annu. Rev. Earth. Planet. Sci. 28, 107-140. doi: 10.1146/annurev.earth.28.1.107

Gudmundsson, A. (2011). Rock Fractures in Geological Processes. Cambridge: Cambridge University Press. doi: 10.1017/CBO9780511975684

Gudmundsson, A. (2012). Strengths and strain energies of volcanic edifices: implications for eruptions, collapse calderas, and landslides. Nat. Hazards Earth Syst. Sci. 12, 2241-2258. doi: 10.5194/nhess-12-2241-2012

Gudmundsson, A., De Guidi, G., and Scudero, S. (2013). Length-displacement scaling and fault growth. Tectonophysics. doi: 10.1016/j.tecto.2013.06.012

Gudmundsson, A., and Mohajeri, N. (2013). Relations between the scaling exponents, entropies, and energies of fracture networks. Bull. Geol. Soc. Fr. 184, 377-387. doi: 10.2113/gssgfbull.184. 4-5.373

Gudmundsson, A., Simmenes, T. H., Larsen, B., and Philipp, S. L. (2010). Effects of internal structure and local stresses on fracture propagation, deflection, and arrest in fault zones. J. Struct. Geol. 32, 1643-1655. doi: 10.1016/j.jsg.2009.08.013

Gurnis, M., Hall, C., and Lavier, L. (2004). Evolving force balance during incipient subduction. Geochem. Geophys. Geosyst. 5. doi: 10.1029/2003GC000681

Hall, C. E., Gurnis, M., Sdrolias, M., Lavier, L. L., and Dietmar Muller, R. (2003). Catastrophic initiation of subduction following forced convergence across fracture zones. Earth Planet. Sci. Lett. 212, 15-30. doi: 10.1016/S0012-821X(03)00242-5

Hall, R. (2002). Cenozoic geological and plate tectonic evolution of SE Asia and the SW Pacific: computer-based reconstructions, model and animations. J. Asian Earth Sci. 20, 353-431. doi: 10.1016/S1367-9120(01)00069-4
Hanks, T. C., and Kanamori, H. (1979). A moment magnitude scale. J. Geophys. Res. 84, 2348-2350. doi: 10.1029/JB084iB05p02348

Hooper, A., Zebker, H., Segall, P., and Kampes, B. (2004). A new method for measuring deformation on volcanoes and other natural terrains using InSAR persistent scatterers. Geophys. Res. Lett. 31. doi: 10.1029/2004GL021737

Jordan, T. H. (2003). Living on an Active Earth: Perspectives on Earthquake Science. National Research Council of the National Academies. Washington, DC: The National Academic Press.

Kim, Y. S., Peacock, D. C. P., and Sanderson, D. J. (2004). Fault damage zones. J. Struct. Geol. 26, 503-517. doi: 10.1016/j.jsg.2003.08.002

Kostrov, B. V., and Das, S. (2005). Principles of Earthquake Source Mechanics. Cambridge: Cambridge University Press.

Leonard, M. (2010). Earthquake fault scaling: selfconsistent relating of rupture length, width, average displacement, and moment release. Bull. Seismol. Soc. Am. 100, 1971-1988. doi: 10.1785/0120090189

Macdonald, K. C. (1982). Mid-ocean ridges: fine scale tectonic, volcanic and hydrothermal processes within the plate boundary zone. Annu. Rev. Earth Planet. Sci. 10, 155-190. doi: 10.1146/annurev.ea.10.050182.001103

Main, I., and Naylor, M. (2012). Extreme events and predictability of catastrophic failure in composite materials and in the Earth. Eur. Phys. J. Special Topics 205, 183-197. doi: 10.1140/epjst/e201201570-x

McFarland, F. S., Lienkaemper, J. J., and Caskey, S. J. (2009). "Data from theodolite measurements of creep rates on San Francisco Bay region faults, California, 1979-2009," in USGS Open-File Report 2009-1119. Available online at: http://pubs.usgs.gov/of/2009/1119/

McKenzie, D. P. (1977). "The initation of trenches: a finite amplitude instability," in Island Arcs, Deep Sea Trenches and Back-Arc Basins. Maurice Ewing Ser, Vol. 1, eds M. Talwani and W. C. Pitman (Washington, DC: American Geophysical Union), 57-61. doi: 10.1029/ME001p0057

Morra, G., Seton, M., Quevedo, L., and Dietmar Muller, R. (2013). Organization of the tectonic plates in the last 200 Myr. Earth Planet Sci. Lett. 373, 93-101. doi: 10.1016/j.epsl.2013. 04.020

Niu, Y., O’Hara, M. J., and Pearce, J. A. (2003). Initiation of subduction zones as a consequence of lateral compositional buoyancy contrast within the lithosphere: a petrological perspective. J. Petrol. 44, 851-866. doi: 10.1093/petrology/ 44.5.851

Peng, Z., and Gomberg, J. (2010). An integrated perspective of the continuum between earthquakes and slow-slip phenomena. Nat. Geosci. 3, 599-607. doi: 10.1038/ngeo940

Pisarenko, V., and Rodkin, M. (2010). HeavyTailed Distributions in Disaster Analysis. Berlin: Springer Verlag. doi: 10.1007/978-90-4819171-0

Ravi-Chandar, K. (2004). Dynamic Fracture. Amsterdam: Elsevier.

Regenauer-Lieb, K., Yuen, D. A., and Branlund, J. (2001). The initation of subduction: criticality by addition of water. Science 294, 578-580. doi: 10.1126/science.1063891

Rolandone, F., Burgmann, R., Agnew, D. C., Johanson, I. A., Templeton, D. C., d'Alessio, M. A., et al. (2008). Aseismic slip and fault-normal strain along the central creeping section of the san andreas fault. Geophys. Res. Lett. 35, L14305. doi: 10.1029/2008GL034437

Schellart, W. P., Freeman, J., Stegmann, D. R., and May, D. (2007). Evolution and diversity of subduction zones controlled by slab width. Nature 446, 308-311. doi: 10.1038/nature05615

Schellart, W. P., Stegman, D. R., Farrington, R. J., and Moresi, L. (2011). Influence of lateral slab edge distance on plate velocity, trench velocity, and subduction partitioning. J. Geophys. Res. 116. doi: 10.1029/2011JB008535

Schlische, R. W., Young, S. S., Ackermann, R. V., and Gupta, A. (1996). Geometry and scaling relations of a population of very small rift-related normal faults. Geology 24, 683-686. doi: 10.1130/00917613(1996)024<0683:GASROA > 2.3.CO;2

Segall, P. (2010). Earthquake and Volcano Deformation. Princeton, NJ: Princeton University Press.

Shipton, Z. K., and Cowie, P. A. (2003). A conceptual model for the origin of fault damage zone structures in high-porosity sandstone. J. Struct. Geol. 25, 333-344. doi: 10.1016/S0191-8141(02)00037-8

Shulka, A. (2006). Dynamic Fracture Mechanics. Singapore: World Scientific Publishing.

Sleep, N. H., and Blanpied, M. (1992). Creep, compaction and weak rheology of major faults. Nature 359, 687-692. doi: 10.1038/359687a0

Stacey, F. D., and Davis, P. M. (2008). Physics of the Earth. 4th Edn. Cambridge: Cambridge University Press. doi: 10.1017/CBO9780511812910

Stern, R. J. (2002). Subduction zones. Rev. Geophys. 40. doi: 10.1029/2001RG000108

Stern, R. J. (2004). Subduction initiation: spontaneous and induced. Earth Planet. Sci. Lett. 226, 275-292. doi: 10.1016/j.epsl.2004.08.007

Sornette, D. (2006). Critical Phenomena in Natural Sciences: Chaos, Fractals, Selforganization and Disorder: Concepts and Tools. Berlin: Springer Verlag.

Sornette, D., and Pisarenko, V. (2003). Fractal plate tectonics. Geophys. Res. Lett. 30. doi: 10.1029/2002GL015043

Stein, S., and Wysession, M. (2003). An Introduction to Seismology, Earthquakes, and the Earth Structure. Oxford: Blackwell.

Sturkell, E., Einarsson, P., Sigmundsson, F., Geirsson, H., Olafsson, H., Pedersen, R., et al. (2006). Volcano geodesy and magma dynamics in Iceland. J. Volcanol. Geotherm. Res. 150, 14-34. doi: 10.1016/j.jvolgeores.2005.07.010

Torsvik, T. H., Muller, R. D., Van der Voo, R., Steinberger, B., and Gaina, C. (2008). Global plate motion frames: toward a unified model. Rev. Geophys. 46. doi: 10.1029/2007RG000227

Turcotte, D. L. (1997). Fractals and Chaos in Geology and Geophysics. Cambridge: Cambridge University Press. doi: 10.1017/CBO9781139174695

Turcotte, D. L., Shcherbakov, R., and Rundle, J. B. (2007). "Complexity and earthquakes," in Treatise on Geophysics, Vol. 4, Chapter 23, ed H. Kanamori (Amsterdam: Elsevier), 675-700. doi: 10.1016/B978-044452748-6.00085-7 
Wells, D., and Coppersmith, K. (1994). New empirical relationships among magnitude, rupture length, rupture width, rupture area, and surface displacement. Bull. Seismol. Soc. Am. 84, 974-1002.

Wright, T. J., Parsons, B. E., and Lu, Z. (2004). Toward mapping surface deformation in three dimensions using InSAR. Geophys. Res. Lett. 31. doi: 10.1029/2003GL018827

Wright, T. J., Sigmundsson, F., Pagli, C., Belachew, M., Hamling, I. J., Brandsdottir, B., et al. (2012). Geophysical constraints on the dynamics of spreading centres from rifting episodes on land. Nat. Geosci. 5, 242-250. doi: 10.1038/ngeo 1428

Received: 02 October 2013; accepted: 22 October 2013; published online: 12 November 2013.

Citation: Gudmundsson A (2013) Great challenges in structural geology and tectonics. Front. Earth Sci. 1:2. doi: 10.3389/feart.2013.00002

This article was submitted to Structural Geology and Tectonics, a section of the journal Frontiers in Earth Science.
Copyright (C) 2013 Gudmundsson. This is an openaccess article distributed under the terms of the Creative Commons Attribution License (CC BY). The use, distribution or reproduction in other forums is permitted, provided the original author(s) or licensor are credited and that the original publication in this journal is cited, in accordance with accepted academic practice. No use, distribution or reproduction is permitted which does not comply with these terms. 